\title{
Adaption of Technological Implementation Towards SMEs' Perlis Performance in Halal Industry
}

\author{
Nainatul Farzuha binti Nor ${ }^{1}$, Hasrul bin Hashom ${ }^{1}$, Nor Izham bin Subri ${ }^{2}$, and \\ Muhammad Anas Zakwan bin Sabri ${ }^{2}$
}

\author{
${ }^{1}$ Language Centre \& General Studies Department, Kolej Universiti Islam Perlis, Malaysia, 01000, \\ ${ }^{2}$ Faculty of Business and Management Science, Kolej Universiti Islam Perlis, Malaysia, 01000, \\ "Corresponding author. Email: nainatul@kuips.edu.my
}

\begin{abstract}
Adaption of Information Communication Technology (ICT) among SME's is becoming more important in enhancing the holistic competitiveness in halal market challenging. Today, Halal food industry is rapidly growing and has contributed to the Malaysia's economic development. Small Medium Enterprise (SME) has taken this opportunity to aim for the achievement in halal food industry. This paper aims to examine the adaption of technological implementation towards SMEs performance in Halal food industry. The methodology used was quantitative method and the questionnaires were distributed among SMEs food supplier at Perlis. SMEs Halal was selected for the study due to the fact that there are currently many ICT service platforms were used for Halal business. The finding demonstrated that the adaption of technology implementation affects SMEs performance. The findings had highlighted the important factors of technology that need to be given attention by the SMEs in order to be more competitive and gain excellence performance in Halal food industry. The implications of this study would contribute to understanding of the technology adoption towards SMEs performance in Halal industry.
\end{abstract}

Keywords: Halal Food Industry, Technology, Firm Performance, SMEs Performa

\section{INTRODUCTION}

The halal food industry can boost both the national and global revenues as a result of increased consumer awareness of Halal products. According to the Minister at the Prime Minister's Department, Datuk Seri Dr Mujahid Yusof, at the opening ceremony of the Summit for the Global Halal (GHAS) at the Centre for International Trade and Exhibition Malaysia (MITEC), the Halal market also includes components of the service sector such as logistics, marketing, media and electronics, packaging, branding and financing, all valued at RM8.57 trillion (US \$ 2.1 trillion). Halal food industry is very important for Muslim and non-Muslims worldwide to ensure the hygiene, cleanliness, safe for consumption and well-made or well-produced, either to be consumed, used and purchased by consumers. The emergence of the Halal food industry as one of the largest consumer food markets has encouraged food manufacturers to implement Halal management system.

However, the performance gap in Halal industry and the unequal focus of performance manufacturer research proves the deficiency of development and understanding about Halal. This is related to the adoption of Halal product in the manufacturing process. The increasing awareness of Muslim and non-Muslim consumer towards Halal food creates a huge demand for this product. Thus, from this awareness, food manufacturing takes a chance to fulfil customer demands because the popularity of, and demand for, Halal certified products among Muslim and non-Muslim consumers which have been on the rise as more consumers are looking for high quality, safe and ethical products. Halal food industry in Malaysia provides a great opportunity for food manufacturers to take part in this industry. The small-to-medium-sized enterprises (SMEs) play a vital role in developing Halal food industry. Hence, SMEs should understand the factors to adopt the Halal productions in the manufacturing processes.

Halal products concept are used as an effective component in terms of consumers' product preferences considering their religious belief to maintain the Halalness of the products, it must be handled by the right person with the right process. Hence, the adoption of Halal products relies on many factors, such as the technology innovation that permits the Halal adoption and performance. Besides, the social influence on the 
increasing demand in Halal consumptions has urged the SMEs to adopt Halal production.

Therefore, halal certification could be a guide to ensure that the halal requirements have been met, including the food quality. The Halal adoption is based on the knowledge on Islamic law by the SMEs. The better the knowledge on halal, would likely pull the SMEs for Halal adoption, and could attract more people to purchase halal food. In addition to that, the awareness on Halal is vital to play a role for Halal adoption by the manufacturers

\section{LITERATURE REVIEW}

\subsection{Halal Food Industry}

Food industry becomes one of the main sources of income for local community in Malaysia. Latest trend in the global business market is the halal industry; because demand for halal product is increasing by both Muslim and non-Muslim consumer. The halal food industry is vital to the Muslims worldwide in order to ensure the hygiene and cleanliness of product for their health and well-being. Demands on shelf life and freshness needed for food are the reason why halal food industry is very attractive.

With the halal food industry growth, Malaysia needs to act fast to improve the effectiveness in halal food industry. The success of the halal food industry, in both domestic and export markets, depends on a broad range of policy developments including those related to the law and regulations, support services and infrastructure, such as human resource development, finance and $\mathrm{R} \& \mathrm{D}$, as well as marketing and promotional efforts.

Hence, Malaysian Government has identified the halal industry as a new source of economic growth and has taken this as an opportunity for Malaysia economic. Malaysian Government has put a key strategy to promote the country as a leading global halal hub. Today, Malaysia has been globally recognized as the leading global halal hub. Malaysia also viewed by other countries as a leading nation in the global halal trade. The most important thing that Malaysian government can do as a hub halal country is compilation of halal certification by food manufacturer. Malaysian government promotes the Malaysian standard and certification as the global benchmarks for halal products as a way to complete the development of a vibrant and competitive halal industry in Malaysia. 2.2 Technology \& Innovation

Describing and measuring innovations generated in the Malaysian in food-based industry is crucial so as to provide an understanding on innovations that has emerged. Presently, more than ever before, global food and agricultural systems are undertaking a process of rapid change. Rising consumer demand and changing
Table 1. Research Demography

\begin{tabular}{|c|c|c|}
\hline Characteristic & Frequency & $\begin{array}{l}\text { Percentage } \\
(\%)\end{array}$ \\
\hline \multicolumn{3}{|l|}{ Ownership Status } \\
\hline Bumiputra & 126 & 94.7 \\
\hline Non-Bumiputra & 7 & 5.3 \\
\hline \multicolumn{3}{|l|}{ Number Of Employee } \\
\hline Less Than 5 & 57 & 42.9 \\
\hline Between 5-75 & 76 & 57.1 \\
\hline More Than 75 & 0 & 0 \\
\hline \multicolumn{3}{|l|}{ Sales Turnover } \\
\hline Less Than 300,000 & 118 & 88.7 \\
\hline Between $300,000-15$ Mil & 15 & 11.3 \\
\hline More Than 15 Mil & 0 & 0 \\
\hline \multicolumn{3}{|l|}{ Business Sector } \\
\hline $\begin{array}{l}\text { Manufacture (Chemical } \\
\text { Production) } \\
\text { Manufacture (Food and } \\
\text { Beverage) } \\
\text { Services (Restaurant) }\end{array}$ & $\begin{array}{c}3 \\
40 \\
11\end{array}$ & $\begin{array}{c}2.3 \\
30.1 \\
8.3\end{array}$ \\
\hline $\begin{array}{l}\text { Services (Transportation) } \\
\text { Services (Warehouse) } \\
\text { Production (Agricultural) } \\
\text { Production (Agro-Based) } \\
\text { Others / Retail }\end{array}$ & $\begin{array}{c}5 \\
1 \\
3 \\
56 \\
14\end{array}$ & $\begin{array}{c}3.8 \\
0.8 \\
2.3 \\
42.1 \\
10.5\end{array}$ \\
\hline \multicolumn{3}{|l|}{ Year Started } \\
\hline Before 2000 & 54 & 40.6 \\
\hline $2001-2005$ & 47 & 35.3 \\
\hline $2006-2010$ & 13 & 9.8 \\
\hline $2011-2015$ & 11 & 8.3 \\
\hline $2016-2020$ & 8 & 6.0 \\
\hline \multicolumn{3}{|l|}{ Business Range } \\
\hline Local & 133 & 100 \\
\hline Regional & 0 & 0 \\
\hline International & 0 & 0 \\
\hline
\end{tabular}

consumer preferences have emerged as key drivers of agricultural prices, technology, and trade.

Global integration of agricultural markets, and supply chains have created new opportunities for distribution of goods, services, and ideas among suppliers, consumers, producers, researchers, and entrepreneurs. These changes have been accompanied by new technology and other fields that have the potential to change the quantity and quality of food and agriculture produced and consumed worldwide.

These rapid changes and emerging conflicts strongly suggest that developing countries will need to develop more responsive, dynamic, and competitive agricultural sectors in the short to medium term to benefit from the changing global system. Agricultural innovation will be the order of the day, and developing countries will need innovative policies, programs, and investments just to 
keep up. Technological expansion within the food system most obviously contributes to the economic effectiveness of the system, mainly through a reduction in product costs and the adaptation of products to consumer criteria. However, the food system has to increasingly answer to broader societal objectives such as sustainable development and many more. Therefore, the implications of innovations within the food system have to be measured through a sustainability outlook.

Innovation has substantial effects upon the food system, such as passing materials more rapidly through the food supply chain; diminishing the impacts of distance for the sourcing of materials; and impacting upon the structure and diversity of the food system. These effects have significant implications for the sustainability of the food system. An interesting aspect of innovation is its capacity both to participate in reforming the current food systems and facilitating the development of new models for food production and consumption.

Food supply chain that operates within a broader system context which is to examine in more detail how the food system is constituted in the global perspective, and especially how technological change will have implications for sustainability. The food sector is a diverse and dynamic one categorized by several trends. This study will critically assess the dynamics between the food system in term of technology, innovation and sustainability.

The population of Malaysia is projected to increase to 35 million in 2020. Feeding a growing population has been translated to a food security challenge. To manage this concern, food productivity has to be increased and agricultural innovation has been proposed to assist in generating new products and/or processes that will enhance the production of livestock and crops.

Previous research indicated the livestock innovation activities in Malaysia are mainly driven by foreign commercial sector focusing on product type inventions. The Malaysian government encourages collaboration between commercial and non-commercial sectors, however, innovation activities on the ground does not seem to indicate so. Although large amount of patenting activities is concentrated in feed-related technologies, feed continues to be the largest single cost item for livestock production in Malaysia, inevitably burdening livestock farmers.

\subsection{Firm Performance}

The notion of firm performance is different from the broader construct of organizational effectiveness. The broader construct includes three corresponding concentric circles, with the largest signifying the organizational effectiveness. The organizational effectiveness covers all facets related to how an organization should function.
Table 2. Descriptive Analysis

\begin{tabular}{|l|l|r|r|}
\hline Item Statistics & Mean & \multicolumn{1}{c|}{$\begin{array}{c}\text { Std. } \\
\text { Deviation }\end{array}$} & \multicolumn{1}{c|}{ N } \\
\hline $\begin{array}{l}\text { Firm } \\
\text { Performance 1 }\end{array}$ & 3.5188 & .86691 & 133 \\
\hline $\begin{array}{l}\text { Firm } \\
\text { Performance 2 }\end{array}$ & 3.6391 & .86461 & 133 \\
\hline $\begin{array}{l}\text { Firm } \\
\text { Performance 3 }\end{array}$ & 3.4286 & 1.03196 & 133 \\
\hline $\begin{array}{l}\text { Firm } \\
\text { Performance 4 }\end{array}$ & 3.5564 & .93269 & 133 \\
\hline $\begin{array}{l}\text { Firm } \\
\text { Performance 5 }\end{array}$ & 2.9850 & .78803 & 133 \\
\hline $\begin{array}{l}\text { Firm } \\
\text { Performance 6 }\end{array}$ & 3.0902 & .85687 & 133 \\
\hline $\begin{array}{l}\text { Firm } \\
\text { Performance 7 }\end{array}$ & 3.9023 & 3.68631 & 133 \\
\hline
\end{tabular}

Business performance or firm performance is a subcategory of organizational effectiveness that very well comprises both operational and financial outcomes. The operational performancee could be observed as a predecessor to financial performance, mediating the effect of resources. While the customer satisfaction may be a predecessor to financial performance, it is in fact a part of customer satisfaction itself. This depends on how researchers describe firm performance for their studies. It is noteworthy to say that in defining the performance, as the satisfaction of stakeholders will help to discern between previous circumstances and performance outcomes. In this case, customer satisfaction is clearly an outcome (using the customer - a stakeholder perspective) and thus become part of firm performance. Besides, in today's exceedingly competitive environment, the organizations need to protect the longterm benefits of customers [5].

For business enterprise, 'profit' is the objective in order for a business to grow and survive in the market. The social objective of public sector could be related to quality of service in which it has the potential to attract the customers. Service Quality is the function of perceptions, expectations and performance of firms. The competitive service quality, in the aggressive competition, is important for survival and for the existence of institutions. 


\subsection{SME's Performance}

According to Small and Medium Industries Development Corporation (SMIDEC), an enterprise is considered as an SME in each of the representative sectors based on the annual sales turnover or number of full-time employees. SMEs are divided into two sectors; manufacturing, manufacturing-related services and agriculture industries; and services (including ICT) and primarily agriculture. Several of the existing literature accentuate various challenges facing the SMEs in a globalized environment, from struggle in facing recession, barrier from global sourcing, low productivity, lack of managerial capabilities, lack of financing, difficulty in accessing management and technology, heavy regulatory burden and others. In the other study, the obstacles to entrepreneurship namely lack of access to credit and lack of access to formal business and social networks. Besides, SMEs are dealing with increased global challenges, new emerging technologies in ICT and in the production process as well as increasing factor costs, which affect the export competitiveness. The SME sector has a key role to play in the continuous recovery of the region arising from the business opportunities created by the restructuring process itself, the movement towards closer regional economic integration, advances in information and communications technology (ICT) and more specifically the business opportunities arising from the Internet.

\section{METHODS}

In this study, every respondent confirmed that their business is only focused on the local market. Only data extracted from an acceptance questionnaire that had been cleaned was utilised in the analysis. Only 133 of the total number of returned questionnaires are useable following the data cleaning process. It was established that 14 questions were rejected because respondents did not finish the responses entirely, and one questionnaire was sent twice by the same company. The questionnaire for this survey was separated into three sections: firm demographics, firm performance, and Level of Technological Implementation (LoTI). There were 15 questions related to LoTI based on 5-point Likert scale. The variables were categorised using the Likert scale, with 1 denoting 'Never', 2 Denoting 'Rarely', 3 denoting 'Moderately', 4 denoting 'Frequently', and 5 denoting 'Very Frequently

\section{RESULT AND DISCUSSION}

This research survey encompasses industries such as food producers, agriculture and basic agriculture, grocery stores, bakeries, restaurants, and small-scale food and beverage production, among others, to define the company kinds. The following are the demographic features of the sample respondents:

According to the results, more than $90 \%$ of respondents fell into the Bumiputra group. The number of employees and sales turnover are used to define each criterion, such as whether they are micro, small, or medium businesses. This criterion classifies firms/businesses with less than 5 employees and a sales turnover of less than RM300k as micro enterprises, firms with more than 5 to 75 employees and a yearly revenue of between RM300k and RM15 million as small enterprises, and so on (smecorp.gov.my). Based on the data collected, $88.7 \%$ of respondents are micro entrepreneurs/enterprises, while just 11.3 percent are small businesses, and no medium businesses participate in or answer to the survey. The data also shows that the majority of the respondents $(42.1 \%)$ worked in agro based industry production, followed by food and beverage manufacture $(30.1 \%)$, retail $(10.5 \%)$, restaurant service $(8.3 \%)$, and a few other businesses with low return on feedback. 85.7 percent of businesses have been in operation for more than 20 years, while just $6 \%$ have been in operation for less than five years.

The reliability statistic Cronbach's Alpha was 0.569). The Cronbach's alpha for the impact of technological

Table 3. Correlation Analysis

\begin{tabular}{|c|c|c|c|c|c|c|c|}
\hline $\begin{array}{c}\text { Film } \\
\text { Performance }\end{array}$ & 1 & 2 & 3 & 4 & 5 & 6 & 7 \\
\hline 1 & 1.000 & 0.868 & 0.783 & 0.699 & 0.566 & 0.620 & 0.063 \\
\hline 2 & 0.868 & 1.000 & 0.879 & 0.768 & 0.626 & 0.648 & 0.060 \\
\hline 3 & 0.783 & 0.879 & 1.000 & 0.829 & 0.567 & 0.530 & 0.103 \\
\hline 4 & 0.699 & 0.768 & 0.829 & 1.000 & 0.455 & 0.487 & 0.064 \\
\hline 5 & 0.566 & 0.626 & 0.567 & 0.455 & 1.000 & 0.664 & -0.042 \\
\hline 6 & 0.620 & 0.648 & 0.530 & 0.487 & 0.664 & 1.000 & -0.031 \\
\hline 7 & 0.063 & 0.060 & 0.103 & 0.064 & -0.042 & -0.031 & 1.000 \\
\hline
\end{tabular}


towards SMEs performance is acceptable since it is 0.869 which is considered to be acceptable. According to [1], a sample size of 25 to 100 respondents is sufficient to determine the instrument's reliability and validity. The number of questionnaires distributed to respondents which directly involves micro, small and medium firms in Perlis. To indicate the internal consistency, the most common measurement tool is the used of Cronbach Alpha coefficient to measure reliability as it is also expected to provide good guidance. The descriptive shows the descriptive analysis for the firm performances. The table presents that the question about performance on firm 7 showed the highest mean is at 3.9023 while the lowest mean is 2.9850 on the question about the performance on firm 7. Secondly, the highest mean is 3.6391 for performance on firm 2. Performance on firm 4 which at 3.5564 and followed by performance on firm 1 at 3 . Business performance is a company's ability to adapt to the business environment, accompanied by changes in the market environment that include customers, competitors and other power forces that can alter the way business works. A good strategy depends on management's ability to create harmony between the environment and internal company [2] so the ability to adapt is important.

Based on this study, published studies have recognized that technologies have a vital role in today's halal food industry. If the food manufacturers adopt technology effectively, it can lead to an improvement in firms' business performance as well as maximizing the benefits of technological which are very important for business performance and success of the manufacturer in the future. As such, a better connection between technology and firm's business performances can be achieved by means of measuring firm performance with return-on investment and returnon asset.

The review reported here covers the themes of innovation and business performance. As regards, the link between innovation and business performance, review of empirical studies shows that, in halal food industry, innovation leads to better performance. Innovation is the key to the competitive advantage for halal food manufacturer. The values created by innovations are often manifested in new ways of doing things or new products and processes that contribute to wealth in halal food industry. For practitioners, the findings from previous researcher reveal that halal food manufacturer can utilize many different forms of innovation capabilities. Some firms rely on their abilities to generate product innovation, while others establish multiple actions that altogether contribute to their innovation capability. Further, firm business performance can be affected by paying attention to innovation capability

\section{CONCLUSION}

The firms' performance is relevant to the strategic management but it does suffer from limited conceptualization and selection of indicators which are based only on convenience, and the lack of appropriate consideration of its dimensionality. This review paper contributes towards the characterization of performance-related measurements. It is true that a comprehensive set of performance data is unavailable but these subjective measures are able to shed more light on the limited objective data [3]. The selection of these dimensions should be able to evaluate the most likely affective dimensions, as suggested [4]. The proper scale is to be developed periodically for the subjective model future expansion and also regarding the use for the refinement of the model, with any additional dimensions and indicators suitable to the firms are added from time to time.

The model, suggested in this paper, has clearly identified to be adept in the technological implementation of said model towards SMEs performance. This type of research has some intrinsic limitations that should be explored in the future research. Besides that, the owners of the firm who have been considered to delimit the scope of this measurement model are the ones that are commonly mentioned by the firm. They have access to the objective data on the firms' performance and they are in a position to use the technology as they see fit to be used.

\section{REFERENCES}

[1] Eden, C., \& Ackermann, F. (1998). Making Strategy. Thousand Oaks, CA: Sage. Fitzgerald, L., \& Storbeck, J. E. (2003). Pluralistic Views of Performance. Management Decision, $41(8)$, 741-750. http://dx.doi.org/10.1108/00251740310496251

[2] Elias, E. M., Saifudin, A. M., \& Othman, S. N. (2016). Halal Awareness and Knowledge Among Muslim'S Student Entrepreneurship Program: a. 2nd Interneational Conference on Business Global \& Social Entrepreneurship, (12-14 March), 1-8.

[3] Jaafar, H.S., Endut, I.R., Faisol, N., Omar, E.N. (2011). Innovation in logistics services - Halal logistics. Paper presented at the 16th International Symposium om Logistics (ISL 2011), Berlin, Germany 10-13July

[4] Nusran, M., Gunawan, Razak, M., Numba, S., \& Wekke, I. S. (2018). Halal Awareness on the Socialization of Halal Certification. IOP Conference Series: Earth and Environmental Science, 175(1). https://doi.org/10.1088/1755$\underline{1315 / 175 / 1 / 012}$

[5] Selvam, M., Gayathri, J., Vasanth, V., Lingaraja, K., \& Marxiaoli, S. (2016). Determinants of Firm Performance: A Subjective Model. International Journal of Social Science Studies Vol. 4, No. 7; July 2 